\title{
STUDIES OF AN URTICARIAL RESPONSE TO BLUE AND VIOLET LIGHT IN MAN
}

\author{
BY H. F. BLUM ${ }^{1}$ AND R. J. WEST \\ (From the Division of Physiology, University of California Medical School, Berkeley)
}

(Received for publication October 23, 1936)

A case of urticaria solare being available for study, it has seemed wise to determine as many of the characteristics of the photo-response as feasible, in the hope that these might ultimately shed light on the obscure etiology of this rare but distressing disease. Preliminary studies of this case by Blum, Allington and West (1) have shown that the individual is sensitive to wavelengths included in the spectral region between 3900 and $5300 \AA$, i.e., in the blue and violet parts of the visible spectrum, radiation from which region of the spectrum elicits no response in normal individuals. The urticaria solare individual responds to short periods of this kind of radiation with an erythema restricted to the irradiated area, followed by an edematous wheal over the same area with spreading erythemal flare when the irradiation is sufficiently intense or prolonged; this response has thus the characteristics of the "triple response " as described by Lewis (2), and we may make the tentative assumption that it occurs as the result of the elaboration of a histamine-like " $\mathrm{H}$ " substance, further evidence for which will be presented in the course of this paper. The response disappears in a few hours, leaving no trace. Ultraviolet radiation shorter than $3200 \AA$ brings forth the same delayed erythema followed by pigmentation that is produced in the normal individual, but no traces of the urticarial reaction characteristic of the response to blue and violet light.

\section{CLINICAL ACCOUNT}

As a clinical report of this case has not been published, the following brief account is included.

The patient, a white male, age 21 , associates the first appearance of abnormal sensitivity to light with a bee sting on the left malar area which occurred May 18, 1934. Severe pain and swelling of the face which subsided in a day or two followed the sting. The sensitivity to light was noticed shortly after.

Previous history reveals no allergic or urticarial dis-

${ }^{1}$ Assisted by a grant from the research funds of the University of California. orders. Prior to the onset of the present difficulty his skin had always responded normally to exposure to light. There is no family history of allergy or light sensitivity.

Physical examination shows a well developed male of average height and weight. $\mathrm{He}$ is a brunette, but the skin is pale from avoidance of light. $\mathrm{He}$ is suffering from a moderately severe indolent papular type of acne vulgaris, and presents scattered areas of tinea versicolor over the upper trunk. There are no other abnormalities. The skin reacts normally to heat and cold. There is no dermatographism.

\section{Laboratory findings}

Blood. Numerous counts have shown an average of about 5,000,000 erythrocytes and 7,000 leukocytes per cu. $\mathrm{mm}$. There is an increase in small lymphocytes up to about 50 per cent, otherwise the differential count is normal. Hemoglobin determination, made with a photelometer, based on the Newcomer standard, was 85 per cent. Spectroscopic examination of the serum for abnormal pigments negative.

Urine. Routine examination and examination for porphyrins were negative on several occasions.

Fasting blood sugar-100 mgm. per $100 \mathrm{cc}$.

Fasting blood uric acid-3.3 mgm. per $100 \mathrm{cc}$.

Wassermann-negative.

Gastric analysis. Alcohol test meal.

$\begin{array}{lcccccccc}\text { Time (minutes): } & \text { fasting } & 15 & 30 & 45 & 75 & 90 & 105 & 120 \\ \text { Pree HCl } & 0 & 0 & 0 & 0 & 0 & 0 & 2.4 & 8.0 \\ \text { Total acidity } & 4.2 & 9.6 & 13.7 & 14.3 & 13.3 & 10.2 & 14.0 & 15.0\end{array}$

Scratch tests for a large variety of food, pollen, and epidermal extracts showed no reactions.

Basal metabolic rate-minus 14 .

\section{METHODS}

General method. The arrangement of the apparatus used in the following experiments is diagrammed in a general way in Figure 1 . It consists of a 500-watt projection type Mazda lamp $A$ placed at a given distance from an opaque screen $B$, which has a circular opening $S$ about $2 \mathrm{~cm}$. in diameter through which an area of the skin may be irradiated. The screen is so fixed that the skin of any desired part of the body may be firmly pressed against it without disturbing the arrangement of the apparatus; thus the distance between $B$ and $A$ is established and reproducible through- 

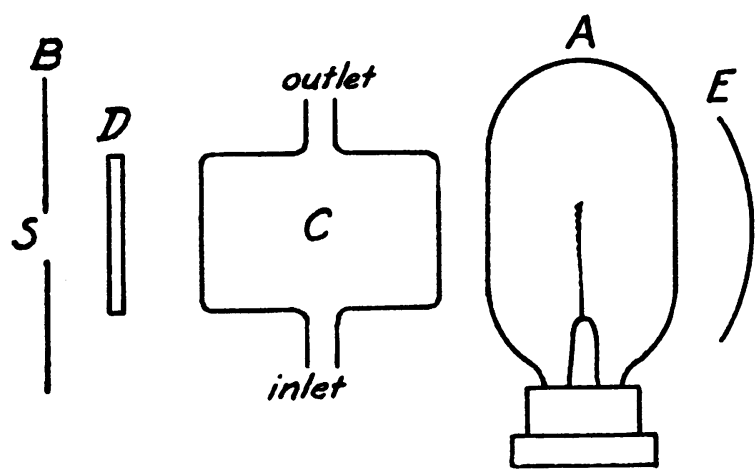

Fig. 1. Arrangement of Apparatus

$A$, 500-watt projection type Mazda lamp; $B$, opaque screen with circular opening $S ; C$, water filter; $D$, glass color filter; $E$, concave mirror.

out a given experiment. $C$ is a water filter for removing infra-red radiation; it consists of a pyrex cylinder $10 \mathrm{~cm}$. in length and $5 \mathrm{~cm}$. in diameter with inlet and outlet tubes so that a current of water may be passed through it to prevent excessive heating of the apparatus. $D$ indicates the position at which glass filters may be introduced to obtain restricted wavelength regions. $E$ is a concave mirror used in some experiments to concentrate the light rays. The distances between the various elements of the apparatus were altered to meet the requirements for any particular experiment, and in some cases one or more of the elements was removed, as will be explained in the description of the different procedures.

The sensitivity of the skin was measured in terms of the time of irradiation required to produce a just observable erythemal response, the threshold time; the justification of this criterion will appear as the various experiments are discussed. The measurement was made in the following way. The skin was placed against the screen $B$, and irradiated through the opening $S$ for a measured number of seconds. The skin was then moved away from the screen and observed for the appearance of erythema on the irradiated area. Most of the experiments were carried out at room temperature and under these conditions it was found that if erythema did not appear within fifteen minutes after the irradiation ceased, none was ever observed. The procedure was repeated on other areas of skin using different periods of irradiation, the shortest period which would just produce an erythemal response being taken as the threshold time. It was found that this threshold time could be determined with an accuracy better than ten per cent in most cases but that it was safer to make no attempt to reduce this error. It is quite easy to make the decision as to whether an erythema has appeared or not, when no greater accuracy is attempted.

The 500-watt projection-type Mazda lamps used as sources burn at a higher color temperature than most incandescent lamps, and consequently have a greater proportion of their emission in the blue-violet region in which we are interested. The shape of the emission curve, being very nearly that of a theoretical black body, can be readily calculated from Wien's equation, if the color temperature is known (see Harrison (3)). Figure 2 shows emission curves for one of the

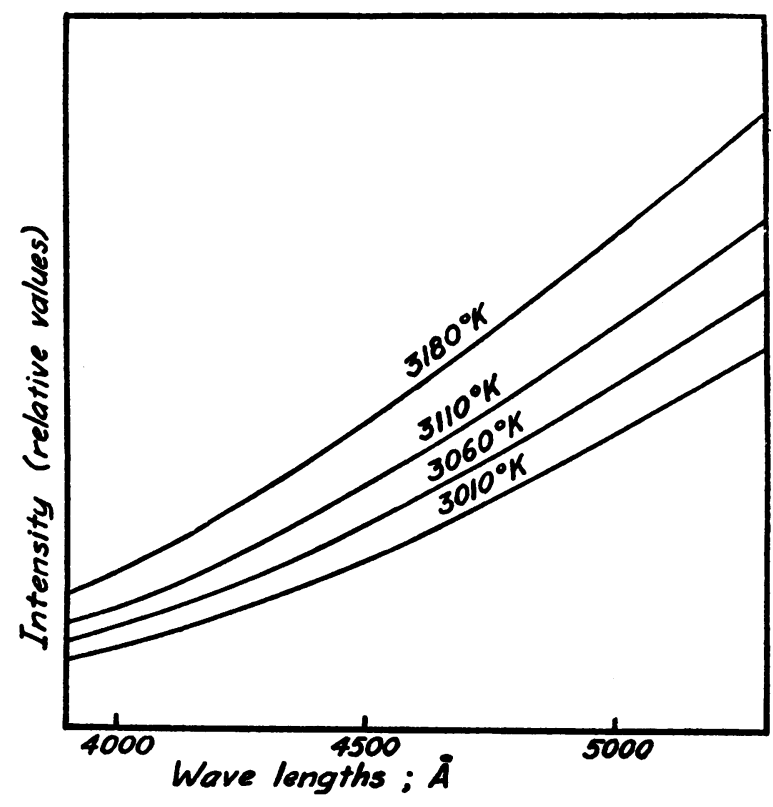

Fig. 2. Spectral Distribution of Emission for a Black Body at Different Temperatures.

The temperatures are the color temperatures for one of the Mazda lamps used, when operated at different voltages as follows:

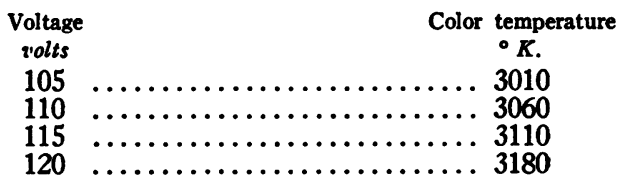

lamps used in the spectral regions with which we are concerned; the four curves are for color temperatures corresponding to four different lamp 
voltages. The color temperatures at different voltages were obtained from photometric determinations against known standards. For most of our experiments we are not interested in the color temperature so long as it remains reasonably constant throughout a given experiment. The total emission varies widely with the voltage, as will be seen from Figure 2, and in order to control this, the line voltage was stepped up by means of a transformer, and the voltage across the lamp controlled by means of a voltmeter and a carbon disk rheostat. The lamp voltage was not the same for all experiments; in some it was maintained at 120 volts and in others at 115 volts; moreover, the distance from the source was not the same in all experiments, and thus the threshold times are not comparable for different experiments but only within a given experiment.

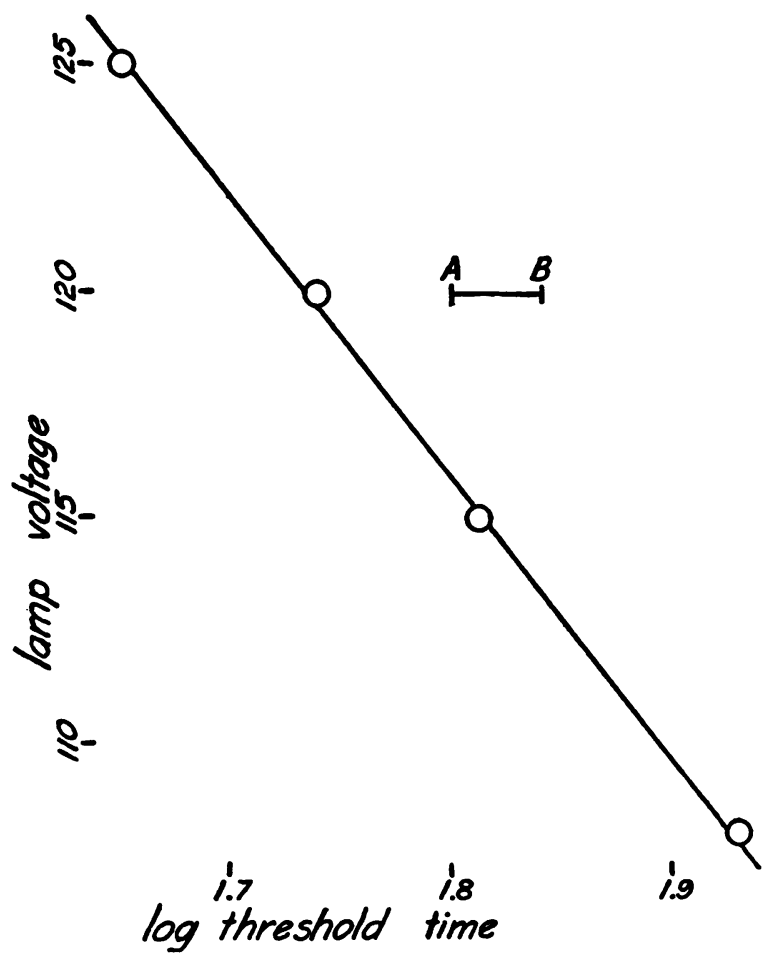

Fig. 3. Relationship of Threshold Time to Lamp Voltage.

$A-B$ indicates a variation of 10 per cent in the threshold time.

While it is possible to make some estimate of the variation of emission with voltage from the curve shown in Figure 2, it was thought desirable to make a more direct determination of the effec- tiveness of the lamp in producing the erythemal response when burning at different voltages. Figure 3 shows the results of an experiment to determine this; the logarithms of the threshold times are plotted so as to indicate the percentage variation in effectiveness of the incident radiation at different lamp voltages; the shape of the curve has no theoretical significance. An examination of the figures shows that if the voltage is held constant within two volts, the error in the threshold time should not be greater than ten per cent. Greater constancy than this was maintained with the exception of occasional slightly greater fluctuations which were of short duration, and probably cancelled out in most cases.

If the lamp is placed close to the skin the full radiation will produce a heat erythema; this appears immediately, and unless severe, fades very quickly. On the other hand, the urticaria solare response is always delayed in appearance unless the irradiation is very intense or prolonged, and is much slower in disappearing. Thus there is little danger of confusing the two types of response. In order to eliminate this heat erythema, which in some cases might confuse our results, we have used the water filter described above to remove the infra-red radiation, or in some cases a Corning glass filter (Number 395, extra light shade Aklo, $3.9 \mathrm{~mm}$. in thickness). The effect of temperature on the threshold time will be discussed below.

The reciprocity law. The use of the threshold time as a measure of sensitivity is only justified if it can be shown that there is a reciprocal relationship between intensity and duration of irradiation. To test this, the intensity was varied by changing the distance between the light source and the skin, the threshold time being determined for each intensity. Since it was found that the water filter ( $C$, Figure 1) served to focus the light rays and thus prevented the estimation of the light intensity by the inverse square law, it was replaced by the Corning glass filter (Number 395, $3.9 \mathrm{~mm}$. in thickness) which served to remove the infra-red radiation to a sufficient extent to prevent the occurrence of heat erythema. It was also necessary to remove the mirror ( $E$, Figure 1$)$. All the tests were made on the skin of the abdomen, where it had been previously determined that the sensitivity was extremely uniform. 
TABLE I

The reciprocity law

$d=$ distance from lamp in cm.; $t=$ time in seconds; $I \times t=k=\frac{1}{d^{2}} \times t$, where $I=$ intensity.

\begin{tabular}{|c|c|c|c|c|c|c|}
\hline $\begin{array}{l}\text { Ex- } \\
\text { peri- } \\
\text { ment }\end{array}$ & Date & $d$ & $t$ & $k$ & Average & $\begin{array}{l}\text { Per cent } \\
\text { devia- } \\
\text { tion from } \\
\text { average }\end{array}$ \\
\hline \multirow[t]{2}{*}{1} & August 29 & $\begin{array}{l}29.8 \\
21.9 \\
15.5 \\
10.0\end{array}$ & $\begin{array}{l}95 \\
65 \\
30 \\
12\end{array}$ & $\begin{array}{l}.103 \\
.136 \\
.125 \\
.120\end{array}$ & \multirow[b]{2}{*}{$.121 \pm .018$} & \multirow[b]{2}{*}{15.0} \\
\hline & & & & & & \\
\hline \multirow[t]{2}{*}{2} & August 31 & \begin{tabular}{|l}
10.0 \\
21.6 \\
50.3 \\
15.3 \\
33.2
\end{tabular} & $\begin{array}{r}14 \\
65 \\
300 \\
30 \\
130\end{array}$ & $\begin{array}{l}.140 \\
.139 \\
.119 \\
.128 \\
.118\end{array}$ & \multirow[b]{2}{*}{$.129 \pm .011$} & \multirow[b]{2}{*}{8.5} \\
\hline & & & & & & \\
\hline \multirow[t]{2}{*}{3} & September 5 & $\mid \begin{array}{l}10.0 \\
50.0\end{array}$ & $\begin{array}{r}14 \\
315\end{array}$ & $\begin{array}{l}.140 \\
.126\end{array}$ & \multirow{2}{*}{$.133 \pm .700$} & \multirow[b]{2}{*}{5.2} \\
\hline & & & & & & \\
\hline \multirow[t]{2}{*}{4} & September 19 & $\begin{array}{l}15.0 \\
30.0 \\
10.0 \\
50.0 \\
20.0\end{array}$ & $\begin{array}{r}31 \\
100 \\
13 \\
300 \\
55\end{array}$ & $\begin{array}{l}.138 \\
.111 \\
.130 \\
.120 \\
.137\end{array}$ & \multirow[b]{2}{*}{$.127 \pm .160$} & \multirow[b]{2}{*}{12.5} \\
\hline & & & & & & \\
\hline
\end{tabular}

The results of four experiments on four different days are summarized in Table $I$. Of these, Experiment 2 was the most carefully conducted and may be taken as a fair index of the accuracy of adherence to the reciprocity law under our experimental conditions. It will be seen that for this experiment, the values for $k$ in the equation: Intensity $\times$ time $=k$ vary from the average by about 8.5 per cent, indicating an outside error of less than \pm 10 per cent. The results for the other experiments, which cover a period of three weeks, show average values for $k$ which agree within \pm 5 per cent, showing that there was little or no fluctuation in the sensitivity over this time; the variations within these experiments are somewhat greater than in Experiment 2. Figure 4 shows graphically the range over which the reciprocity law holds and the deviation of our experimental measurements. It would seem from these data that we may safely assume that the reciprocity law holds for the urticaria response, and that the threshold time may be used as a

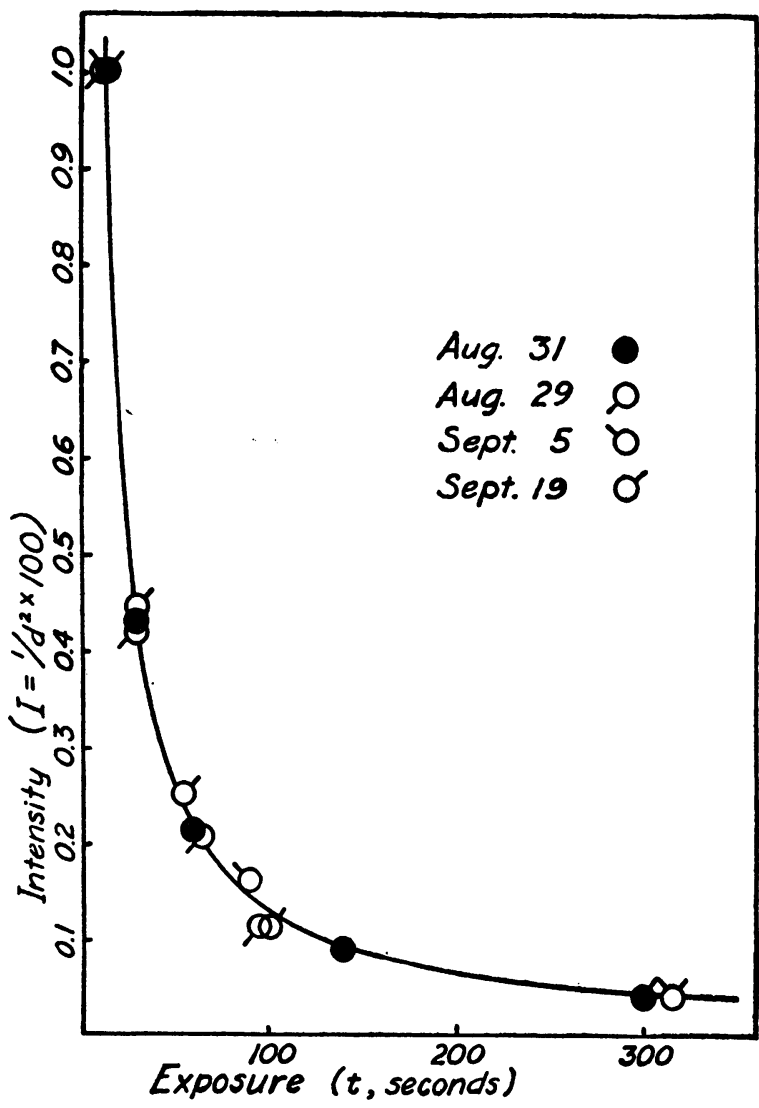

Fig. 4. The Reciprocity LaW.

The curve is drawn from the equation: $I \times t=0.129$.

measure of the photosensitivity with an error of not more than \pm 10 per cent if the conditions are properly controlled.

A point of practical importance to the patient as regards artificial illumination may be mentioned here. From the above data one may calculate that at a distance from the lamp of 3 meters, 3 hours of irradiation would be required to produce a response. Since the lamps ordinarily used for illuminating purposes burn at lower temperatures, their emission is less, and particularly in the shorter wavelengths to which this individual is sensitive. Thus, ordinary conditions of artificial lighting are not bothersome, although even reflected sunlight in a room with light colored walls may be a source of considerable annoyance.

We may make a rough estimate of the quantity of radiation required to produce the response. From the data given by Luckiesch (4) we find 
that a black body at $3200^{\circ} \mathrm{K}$. emits 6.12 microwatts per square centimeter per foot-candle in the spectral region 4000 to $7600 \AA$. The color temperature of a tungsten lamp is very close to that of a black body at this range of temperatures (Holladay (5)) so that this value may be taken as sufficiently close for our purposes. From the curve for emission of a black body at this temperature it may be calculated that between onesixth and one-seventh of the emission between $4000 \AA$ and $7600 \AA$ lies between $4000 \AA$ and $5000 \AA$, the spectral region which elicits the urticaria solare response, so that we may estimate that about one microwatt per sq. cm. per foot-candle is emitted in this region. Our lamp emits about 1300 horizontal foot-candles, and from our data for the reciprocity law we see that at a distance of one foot, the threshold time is about one minute. Thus we may estimate that approximately 1300 microwatts of radiant energy of wavelengths 4000 to $5000 \AA$ must fall on the skin of this individual in order to produce an urticarial response in one minute.

The effect of temperature on the response. It was recognized early in the investigation that temperature might have a considerable influence on the response under certain circumstances. Studies were therefore attempted to determine the magnitude of this effect so that an estimate of the influence of temperature on the accuracy of our measurements might be made.

The effect of temperature on the threshold time was first determined. For these experiments the stop $B$ was replaced by a thin black paper stop with a $2 \mathrm{~cm}$. hole, placed tightly against the water filter $C$, no color filters $(D)$ being used. The skin of the abdomen was held firmly against this black paper so that the skin area next to the water filter would tend to take the temperature of the water which could be varied by passing different mixtures of hot and cold tap water through the filter. The temperature of the filter was determined by means of a thermometer placed in the outlet stream from the filter, and the surface temperature of the skin corresponding to any given filter temperature was estimated as follows. The skin was held against the filter for a given period of time, then moved away, the time noted, and the surface skin temperature determined as quickly as possible by means of a thermopile designed for this purpose, the time at which the measurement was made being carefully noted. Further measurements were made at successive intervals as the skin temperature changed toward the normal, and from these successive measurements a curve was plotted and an extrapolation made to zero time which should correspond to the temperature of the skin when in contact with the filter. It was found that for periods shorter than five minutes in contact with the water filter the values obtained for skin temperature varied considerably, but that when the skin was allowed to remain in contact for periods as long as twenty minutes, the values were very little different than those obtained for the five-minute periods. In our subsequent experiments we therefore kept the skin in contact with the filter for five minutes before the beginning of each experiment, i.e., before beginning the irradiation of the skin. From data obtained for the skin surface temperature at various filter temperatures we were able to plot the curve shown in Figure 5, from which an estimate of the skin surface temperature could be made by merely measuring the temperature of the water at the filter outlet. It is doubtful if these estimates for the skin surface temperatures can be regarded as within better than one or two degrees of the actual skin surface temperature, and the temperature inside the skin where the response takes place must have been somewhat different than those of the skin surface. It would seem that the range of temperatures inside the skin would be somewhat less than those on the surface, but we have no way of estimating this difference.

Measurement of the threshold time at different temperatures was made as follows. The skin was held against the filter for a period of five minutes in order to establish the temperature of the skin. The lamp was then turned on for a given irradiation period, the skin being maintained in contact with the filter during this time. The skin was then moved away, and allowed to adjust toward normal temperature while observation for the appearance of a threshold erythemal response was made. By repeating this procedure for different periods of irradiation, the threshold times for the response at given temperatures were determined. Data for a series of such measurements are plotted 


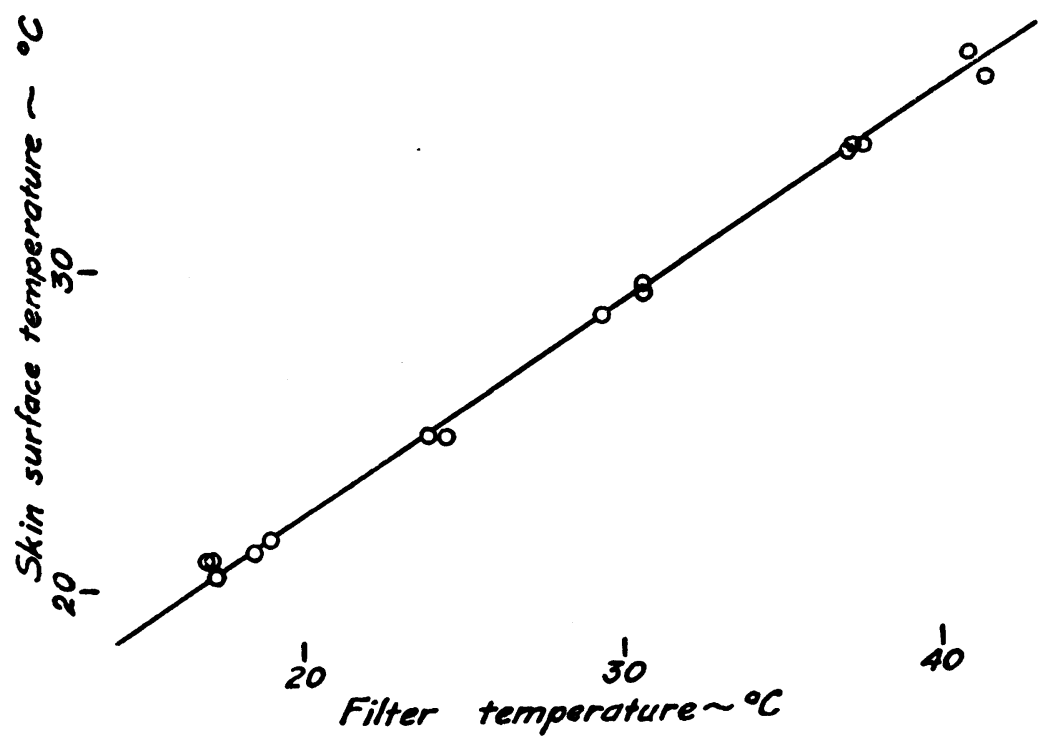

Fig. 5. Relationship of Filter Temperature to Skin Temperature.

in Figure 6. From these data it appears that the $Q_{10}$ for the threshold time is about 1.3 to 1.4 over the range studied. This is a quite reasonable coefficient for a photochemical reaction.

Reference to Figure 6 will give some indication of how differences in temperature may affect the experimental determination of threshold time in the rest of our experiments. We may assume that the normal temperature of the skin surface of the abdomen when exposed to ordinary room temperatures is about $30^{\circ} \mathrm{C}$., and in this region we see that a change of about $3^{\circ} \mathrm{C}$. would result in a variation of 10 per cent in our measurements of threshold time. This is a much greater tem-

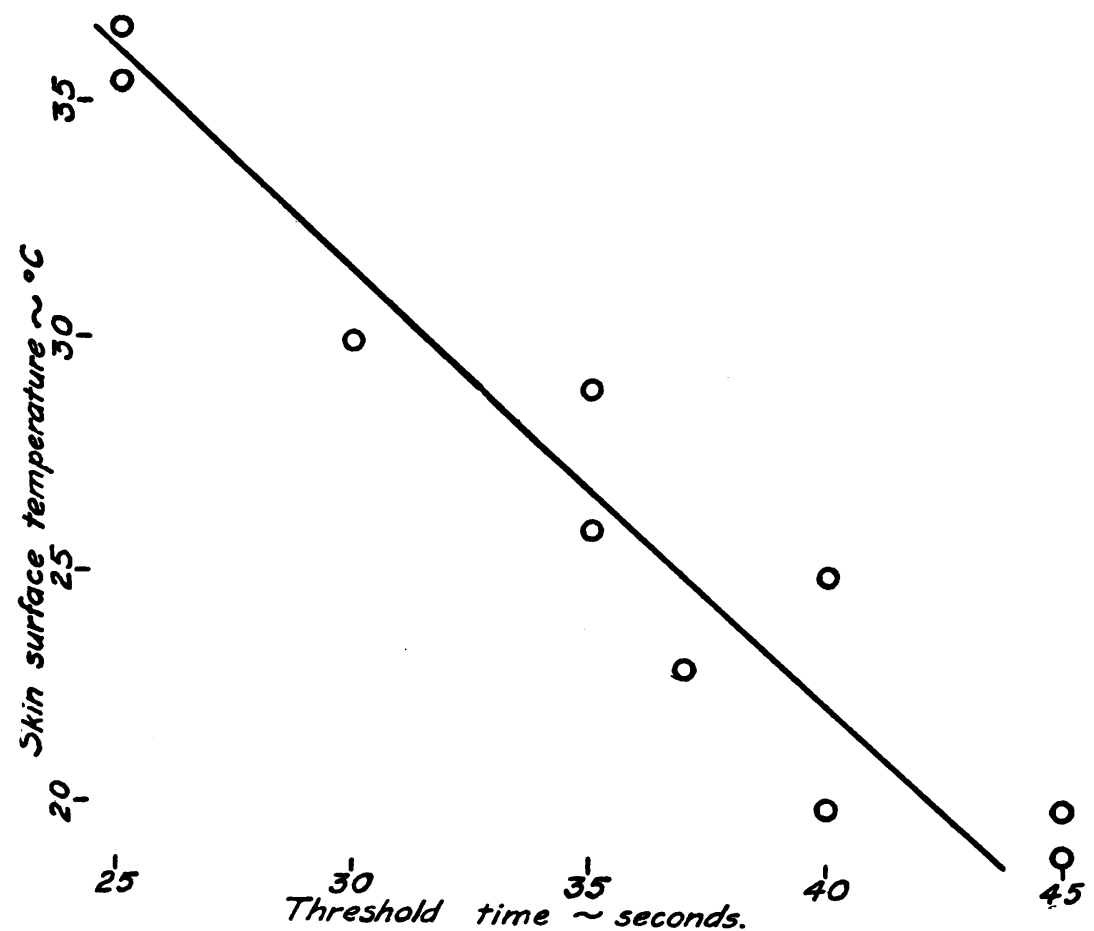

Fig. 6. EFfect of Temperature on Threshold Time. 
perature variation than is to be expected if the room temperature is maintained reasonably constant as was the case in our experiments, but we see that temperature variation is a factor which cannot be entirely neglected, particularly in comparing experiments made on different days.

The low temperature coefficient of the threshold time would indicate its rather direct relationship to the primary photochemical mechanism. However, the rate of development of the urticarial response as indexed by its latent period is not taken into account in the measurement of threshold time. using the same period of irradiation, but a shorter total period in contact with the filter, or if the erythema is not present, the total period is increased. By a series of such trials the least time required for a minimal erythema to appear is determined and may be taken as an index of the rate of development of the erythemal response for the given temperature and period of irradiation. By repeated experiments using different temperatures and different periods of irradiation a series of such measurements were obtained which are displayed in Figure 7. Since the primary photo-

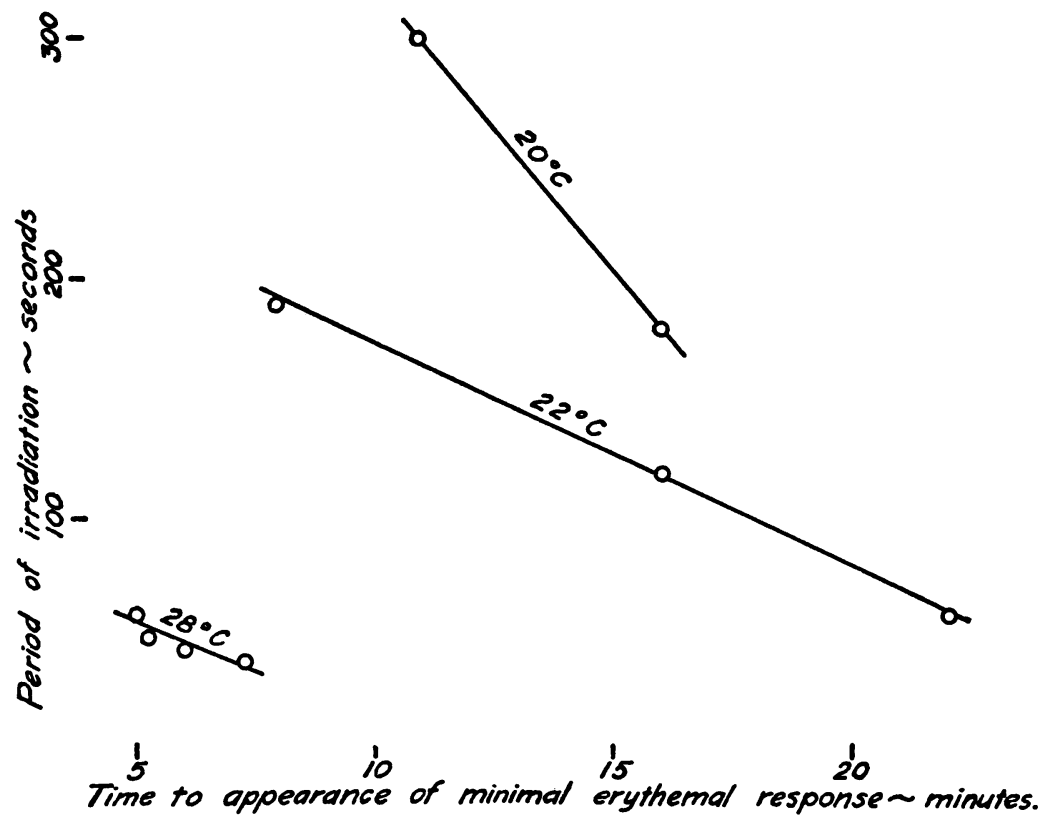

Fig. 7. Effect of Temperature on Latent Period.

The latent period is shortened as the period of irradiation is decreased. We have attempted to measure the effect of temperature on the rate of development of the erythemal reaction after the end of the irradiation period, as follows. The skin is held against the water filter for five minutes, the lamp then turned on, and irradiation continued for a given length of time which is known from the data of Figure 6 to be longer than the threshold time for the particular temperature. When the lamp is turned off, the skin is kept in contact with the filter for a further period of time, and is then moved away and observed for the minimal erythemal response. If the erythema is observed to be present at the time the skin is moved away from the filter, the experiment is repeated chemical reaction has a low temperature coefficient, the period of irradiation may be taken to represent the production of the same quantity of reactants at all temperatures used, and the rates measured for different temperatures when the same period of irradiation was used should be subject to comparison. Unfortunately, these measurements are laborious and trying to the subject, and the measurements which we have made are scanty and rough for this reason; they seem, however, to be significant.

The data collected in Figure 7 show that the time of appearance of the threshold erythemal response is greatly lengthened at low temperatures. In fact, the effect is so great that it is difficult to obtain comparable data over a wide range of 
temperatures, and no attempt has been made to calculate the temperature characteristics of this response. Furthermore, when a temperature of $35^{\circ} \mathrm{C}$. was maintained in the filter and the skin kept in contact with it for a long enough period of time (over seven minutes), no response appeared, so that the temperature coefficient could not be determined in this region. Our results would seem to be quite comparable to those obtained by Lewis (2, Chapter VII), who found that either low ( 12 to $15^{\circ}$ C.) or high ( 45 to $47^{\circ}$ C.) temperatures inhibit the appearance of the triple response following histamine pricks in normal individuals, or stroking in urticarial subjects. Lewis has explained this as due, in part at least, to changes in the local circulation produced by changes in temperature, and if we invoke the same explanation it would seem meaningless to attempt to determine the temperature characteristics accurately, since they would not be an index to the specific reactions of urticaria solare, but of more general reactions.

Lewis has suggested that the triple response in other types of urticaria results from the release of a histamine-like $H$ substance from the cells of the skin, and it seems reasonable to extend this concept to urticaria solare. The similarity of behavior with respect to temperature is added evidence to justify this position. We might, then, suggest the following scheme to represent the mechanism of urticaria solare:

$$
\begin{aligned}
& \text { 1. } S+h_{\nu} \rightarrow S_{r} \\
& \text { 2. } S_{r}+\text { cells } \rightarrow H \\
& \text { 3. } H+\text { vessels } \rightarrow \text { triple response }
\end{aligned}
$$

In the primary reaction, $1, S$ is the light absorbing molecule in the skin which is responsible for the initiation of the response, $h v$ is a quantum of light absorbed by $S$ ( $h=$ Planck's constant and $v$ the frequency of the radiation), and $S_{r}$ the reactive molecule resulting. By $S_{r}$ we do not wish to imply an activated molecule in the strict photochemical sense, but merely to indicate that the molecule $S$ has been in some way modified and enabled to take part in a subsequent reaction. In reaction $2, S_{r}$ reacts with skin cells to release the histamine-like substance $H$, which then reacts with the small blood vessels to produce the triple response 3 . Obviously reaction 2 may be a chain reaction involving many steps. Reaction 1 must have a very low temperature coefficient since it is a purely photochemical reaction, and its rate is not dependent on the energy of activation but on the capture of light quanta. However, reactions 2 and 3 are thermal reactions and may have high temperature coefficients. It seems probable that reaction 3 is the one which dominates the picture when the effect of temperature on the rate of appearance of the urticaria solare response is studied, because of the similarity of behavior to that obtained when histamine is introduced directly into the skin. The temperature coefficient obtained for the threshold time is probably determined principally by reaction 1 which would account for its low value; reaction 3 probably plays little part in the determination of the threshold time where the temperature is only maintained during the period of irradiation, and the development of the response takes place at approximately normal skin temperature.

TABLE II

Sensitivity on various regions of the body, December 3, 1935

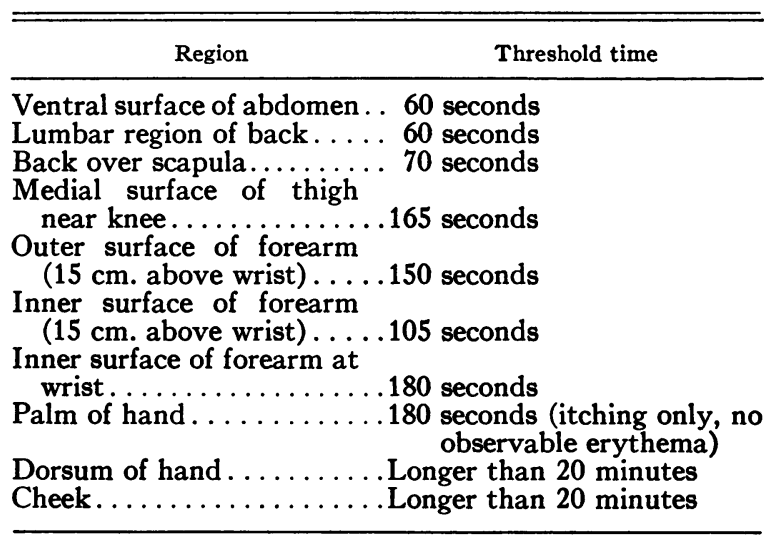

Topographical distribution of photosensitivity. Determinations of the threshold time for a number of regions of the body are given in Table II. A constant light intensity was maintained throughout, and all the determinations were made within a period of three hours. The sensitivity varies widely over the body, the abdomen and lumbar region of the back being at least twenty times as sensitive as the face and the back of the hands. The surface of the abdomen is uniformly sensitive within the limits of our experimental error, and we have used this region in all our other experiments. It is of interest to note how the sensitivity may vary in adjacent regions, e.g., compare 
the palm and dorsum of the hand. Although we were unable to produce any erythemic response by exposure of the face and dorsum of the hands to our light source for twenty minutes, it must not be judged that these parts have become entirely insensitive, for the response can still be elicited by exposure to sunlight, and the subject is still made uncomfortable by such exposure, although to a much less extent than two years ago. Unfortunately, no measurements of this kind were made early in the development of the disease, the figures in Table II being obtained about nine months after its onset. We cannot, therefore, make a definite statement that the decreased sensitivity of the exposed parts has developed as a result of exposure to light; but judging from the subject's reaction to casual exposure to sunlight at the onset and at present we feel no doubt whatsoever that this is true. Moreover, Duke (6), Vallery-Radot (7), and Blum, Allington and West (1) have all found that exposure to light has some effect in decreasing the sensitivity of the skin to light.

Numerous possibilities offer themselves for the explanation of the difference in sensitivity of various regions of the skin, and the mechanism of desensitization of local areas. Among these arises the question of the thickness of the skin, and its relative transparency to light. Miescher (8) has pointed out that the thickness of the skin is very important in determining the sensitivity of normal skin to the erythema producing ultraviolet radiation (principally shorter than $3200 \AA$ ), and that the decrease in sensitivity to such radiation after exposure to it, may be due to the thickening of the epidermal layers. The data of Bachem and Reed (9) for the absorption of different wavelengths of light by the various layers of the skin, afford the opportunity to make some estimate of the effect of the thickness of the epidermis on the normal erythemic response and on the urticaria solare response. The normal erythemic mechanism would seem to be set off in the epidermis, probably chiefly in the malpighian layer, since there is very little penetration ( 9 to 16 per cent) of the exciting wavelengths below this layer, since the malpighian layer is the principal site of pigment deposition which follows the erythema (Laurens (10)), and since the erythema is delayed as though time might

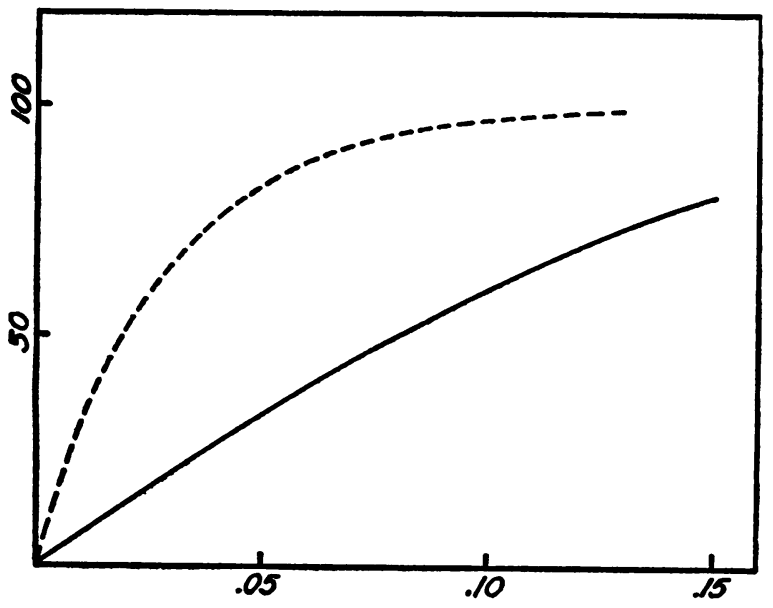

Fig. 8. Effect of Thickening of Skin on PenetraTION OF RADIATION.

Abscissa-thickening in mm. Ordinates-per cent reduction in radiation reaching the photosensitive layer. Broken line- $3000 \AA$, malpighian layer (normal erythemic response). Solid line- $4500 \AA$, papillary layer (urticaria solare).

be required for the products resulting from the irradiation to reach the papillary layer where the first blood vessels are found. In Figure 8 has been plotted the percentage reduction in radiation of wavelength $3000 \AA$ reaching the malpighian layer which would be caused by thickening of the corneum, based on the data of Bachem and Reed which is for skin from the region of the flexor surface of the arm and the abdomen. It will be seen that a thickening of $0.03 \mathrm{~mm}$., which amounts to doubling the thickness of the corneum, would reduce the radiation reaching the malpighian layer by about 66 per cent, so that an amount of thickening which would be difficult to observe would cause a considerable difference in the sensitivity of the skin to radiation of this wavelength. Thus small differences in the thickness of the skin at different regions of the body would produce marked variations in sensitivity, and it is conceivable that thickening resulting from irritation caused by irradiation would account for at least part of the resistance of the skin to ultraviolet radiation subsequent to exposure (Laurens (10)).

The case of the urticaria solare response is somewhat different, the radiation which evokes it being transmitted by the skin to a much greater extent. The response appears almost immediately after the irradiation, in contrast to the response 
elicited by ultraviolet light, which suggests that the locus of action is close to the small vessels which first appear in the papillary layer. Upon reference to the data of Bachem and Reed (9), we find that only about 20 per cent of the total light of wavelengths 4000 to $5000 \AA$ incident upon the skin is absorbed in the epidermal layers, but that 50 per cent is absorbed in the papillary layer, so that it is quite possible that the urticaria solare response is elicited in the latter layer. In Figure 8 is plotted the percentage decrease in radiation of wavelength $4500 \AA$, which results from increasing the thickness of the epidermis; this indicates that the thickness of the epidermis should have much less effect on the urticaria solare response than on the erythemic response to ultraviolet radiation. From Figure 8 it may be seen that a thickening of $0.1 \mathrm{~mm}$. which amounts to tripling the thickness of the epidermis would be required to reduce the light reaching the papillary by 60 per cent. While differences in the thickness of the skin might be an important factor in determining the threshold time for the various regions of the body, it is improbable that it is a very important factor in the desensitization of the skin.

Blum, Allington and West (1) found that successive irradiation of an area of the skin with the quartz-mercury arc in quantity sufficient to produce a strong pigmentation reduced the sensitivity of that area to a marked degree. A filter was interposed (Corning 986) to remove the radiation above $4000 \AA$, so that the urticaria solare response was not elicited during the building up of the pigment. As we have pointed out above, thickening of the epidermis could hardly account for a large part of the decrease in sensitivity. The pigment, which is deposited in the basal cells of the malpighian layer of the epidermis, may be very effective as a filter if the urticaria solare response originates in the papillary layer provided it absorbs strongly in the blue-violet region, and may conceivably be the cause of the apparent desensitization in the experiment of Blum, Allington and West. However, at the time the tests recorded in Table II were made, the face of the subject showed very little pigmentation so that the lack of sensitivity of this region could not be credited to any extent to this factor.

Another possibility is that the exposed areas of skin in which the urticarial response has been frequently produced by the action of light, has decreased in sensitivity to the products of the photochemical reaction; for instance, its sensitivity to histamine. This was tested by pricking histamine into various regions of the skin, and comparing the reaction with that of a series of normal individuals. $^{2}$ The subject's reactions to histamine were within normal limits on all parts of the body including the exposed parts. The sensitivity to histamine is normally less on the exposed parts, but the difference is not of the order of the difference in sensitivity to blue-violet light shown by our subject. Reactions to adrenalin pricks were also within normal limits. Thus we have no reason to suspect an abnormal vascular reactivity in the subject.

Finally, we come to the concept that exposure to light exhausts some part of the photochemical mechanism. This is the suggestion of Duke (11). We must admit this as a distinct and reasonable possibility, but one that cannot be categorically accepted in face of the other possibilities cited above, unless further proof can be found. The fact that Blum, Allington and West (1) were able to produce a decrease in sensitivity by ultraviolet irradiation without eliciting the urticaria solare response demonstrates that some other factor is involved than the wearing out of the photochemical mechanism. It is probable that all the factors mentioned play a part in decreasing the sensitivity of the skin which is exposed intermittently to sunlight.

Variations in the general sensitivity with time. An attempt was made to follow the sensitivity of a region of the skin normally covered by clothing, the abdomen, over the course of ten months. These determinations were subject to a greater error than our other studies, because it was impossible to use the same lamp throughout the entire series, and because in some cases the voltage was not carefully controlled. Moreover, at the time of the earlier measurements we were not aware of some of the possible errors in the detection of the threshold. In general, the later determinations are more trustworthy, but it is difficult

\footnotetext{
2 These tests were made through the courtesy of Dr. Eric Ogden who will publish an account of the method and results of a series of such tests at a subsequent time.
} 


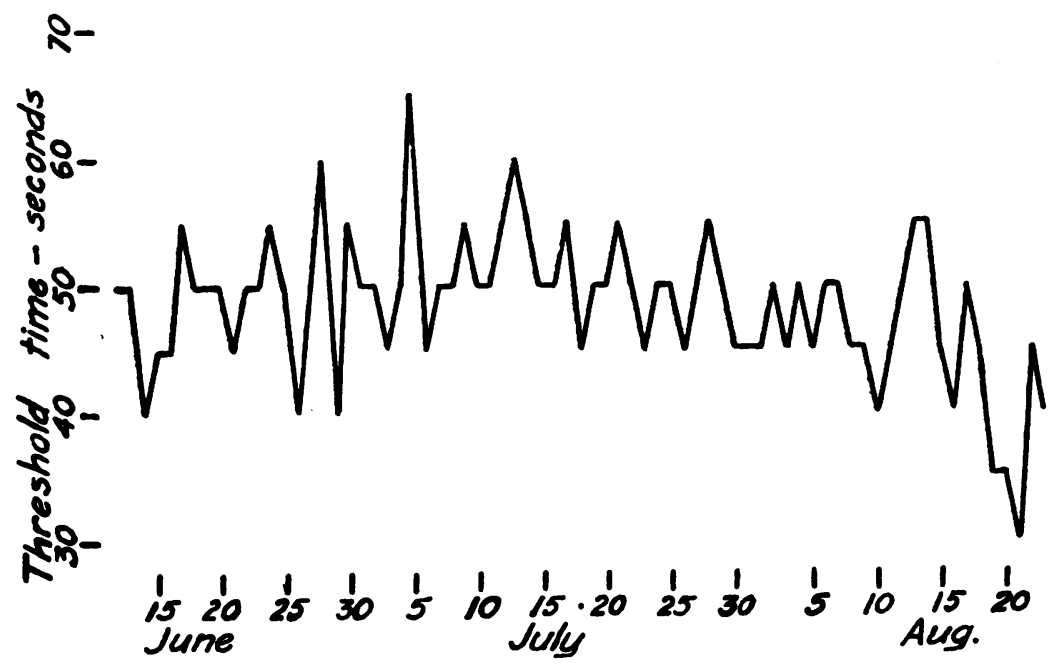

Fig. 9. Variation of Threshold Time during a Period of Two Months.

to see how the error could be greater than 50 per cent throughout the series. Figure 9 shows a series of measurements carried over a period of three months which are probably comparable. It shows no general trend of sensitivity over the whole period of three months, but demonstrates that there are fluctuations of short duration which are undoubtedly greater than the estimated error. These results indicate that it is probably important to perform a given experiment on a single day, and this has been our policy. They also indicate that in any attempt at therapy one should not be misled by minor changes in sensitivity which may be only ephemeral.

The relative stability of the photosensitivity indicates that the photochemically active substance, whatever its nature, is constantly renewed. It may be a product of abnormal metabolism, a substance elaborated by a parasite, or a substance regularly introduced in the diet. In consideration of the latter possibility, some attempt was made to eliminate various factors from the diet, but without any observable effect on the photosensitivity.

Miscellaneous skin tests. As has been indicated in the preceding discussion, there is no reason for believing that an allergic reaction in the usual sense of the word is involved in the urticaria solare response. The only assumptions which are necessary to explain the response are that a photoactive substance is abnormally present which, when activated by light, initiates reactions which result in the production of a histamine-like substance. Nothing is definitely known about the intermediate steps except that they are not of the "photodynamic" type since they do not require molecular oxygen as was shown by Blum, Allington and West (1) and Blum, Watrous and West (12). There seems no reason for assuming that they are related to allergic reactions, but we have searched for an allergic background since it is commonly suspected in urticarial cases. No history of allergy either in the patient or members of his family was obtained, and scratch tests with a large number of food, pollen, and epidermal extracts gave only negative results. Reactions to heat and cold and to stroking are normal, and there is no dermatographism. Thus no evidence of an allergic background for this condition has been found.

Passive transfer of the sensitivity was attempted by intradermal injection of serum from the patient into normal skins. In preparing the serum, the active blue-violet light was excluded, in order that any photolabile substance might not be destroyed. No uniform differences were found between the reactions to this serum and those to serum from a normal individual. The serum was then exposed to light and the injections repeated, but with similar results. Exposure of the injected area to light also failed to provoke any abnormal response.

Prompted by the close association of a bee sting with the onset of the photosensitivity we tested the patient's sensitivity to an extract of bee 
venom, prepared as suggested by Thompson (13) by triturating the poison apparatus in normal saline and filtering through a Seitz filter. Onetenth cubic centimeter of a solution estimated to contain 1 to 1500 parts of venom when injected intradermally provoked a wheal approximately one centimeter in diameter showing free pseudopodia. In normal individuals the usual result is an erythematous papule less than half this size, so that the patient seems somewhat sensitive to bee venom. Suspecting some relationship between this sensitivity to bee venom and to light, attempts were made to desensitize the patient by a series of injections of the dilute bee venom solution, but without any definite effect on the sensitivity of the patient to light. Simultaneously and subsequently the patient was given hydrochloric acid by mouth to correct a condition of achlorhydria, but no change in sensitivity to light resulted.

The active wavelengths. As stated above, the preliminary studies by Blum, Allington and West (1) delimited the wavelengths which produce this urticarial response to the region between 3900 and $5300 \AA$, which is in very good agreement with the findings of Duke (6), Vallery-Radot (7), and Frei (14) for their cases. We must assume that whatever the ultimate chemical reaction which produces this urticarial response, the primary reaction is the absorption of a quantum of light by a molecule of some photoactive substance in the skin as represented in reaction 1 above, and whatever this substance may be, it must have a characteristic absorption spectrum, i.e., there must be only restricted regions of the spectrum which it can absorb, and consequently only light of these spectral regions can bring about the urticarial response. We dwell upon this fundamental point because it has been too frequently disregarded in the study of photosensitivity in man. The relative sensitivity to different wavelengths should correspond to a certain degree with the amount of light absorption of the photosensitizing substance, and the curve relating sensitivity and wavelengths should approximate the absorption spectrum of that substance. There are, of course, a number of factors which would tend to produce some disagreement in these curves, such as the effect of the solvent on the absorption spectrum of the photoactive substance, the specific absorption of the skin, variations in photochemical efficiency with wavelength, etc.; but if we are able to obtain a sensitivity wavelength curve for the photodermal response, we have a basis for a guess as to the nature of the photosensitizing substance. For this reason we have attempted to make some more quantitative determinations than those previously reported.

In these studies colored glass filters were used to isolate relatively narrow bands of wavelengths. The transmissions of the various filter combinations were determined for the visible region of the spectrum by means of a spectrophotometer. Since we had already determined by means of glass color filters (Blum, Allington and West (1)) and sunlight or quartz mercury arc that wavelengths outside the 3900 to $5300 \AA$ region were ineffective, we could disregard any filter transmission outside of this restricted region. The spectrophotometric measurements could not be made for wavelengths shorter than $4300 \AA$, and it was necessary to extrapolate to zero transmission beyond this point, but our preliminary determinations would indicate that the sensitivity below this wavelength is so slight that no significant error could have been introduced.

The lamp used in these particular experiments was the one whose emission curves are plotted in Figure 2; it was operated at 120 volts, at which voltage the color temperature was $3180^{\circ} \mathrm{K}$. The emission curve was calculated for a black body at this temperature by means of Wien's equation (see Harrison (3)), and the transmission of each filter combination for given wavelengths was multiplied by the emission for the corresponding wavelengths; thus curves were obtained for the relative quantities of radiant energy incident through the various filters. A further correction was made to give a relative number of quanta by multiplying by the wavelength of the radiation. ${ }^{3}$

\footnotetext{
8 Since the amount of photochemical reaction depends upon the number of quanta absorbed by the photochemically active substance $S$, it is proper to compare the relative number of quanta rather than the relative energies corresponding to the exciting wavelengths. The correction is so small in this case as to be of little significance, however. The subject is discussed by Blum and Scott (15), in which paper Equation 8 should read: $N \lambda^{\prime}=$ $I_{\lambda} S_{\lambda} T_{\lambda}\left(-\log T_{\lambda}\right)$.
} 


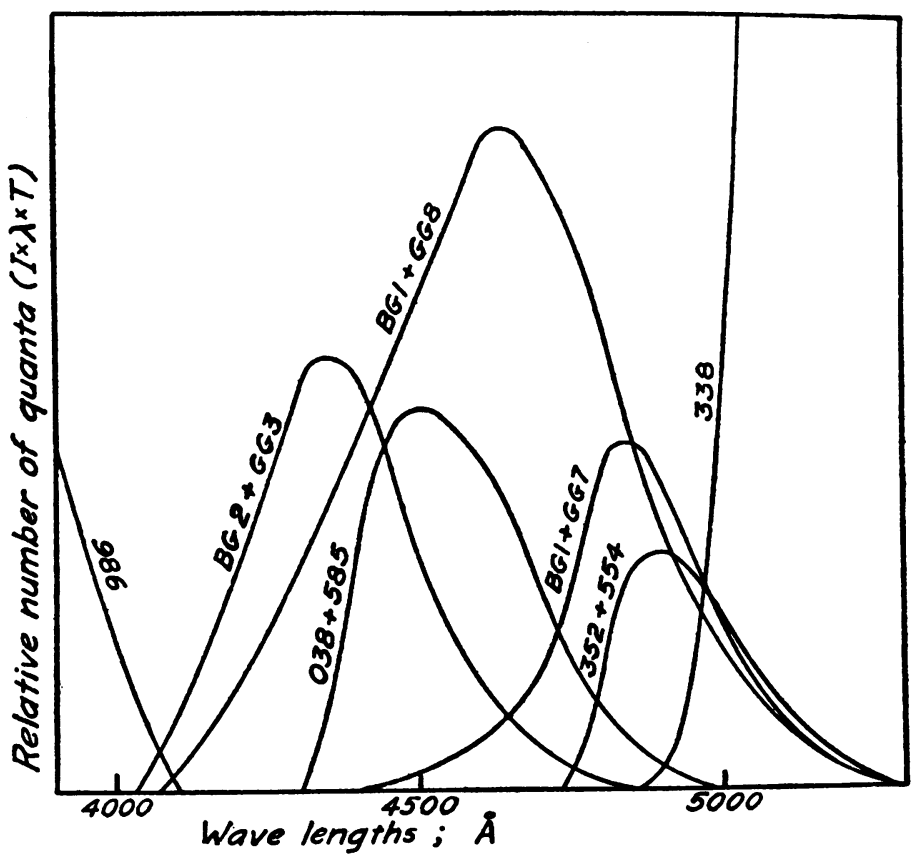

Fig. 10. Light Passing through Filters Used to Isolate Spectral Regions.

The curves for the relative number of quanta passing through the filter are shown in Figure 10.

TABLE III

Photosensitivity to restricted spectral regions

(Experiments 1, 2, and 3 were performed on October 12, October 29, and October 30, respectively)

\begin{tabular}{|c|c|c|c|c|c|c|}
\hline Filter & $\underset{\text { imum }}{\lambda}$ & $A$ & $\begin{array}{l}\text { Ex- } \\
\text { peri- } \\
\text { ment }\end{array}$ & $t$ & $k_{\lambda}=A \times t$ & $\frac{1}{k \lambda}$ \\
\hline \multirow[t]{2}{*}{ BG2 + GG3 } & \multirow[t]{2}{*}{$\underset{4350}{\AA}$} & \multirow[t]{2}{*}{.44 } & \multirow[t]{2}{*}{$\begin{array}{l}1 \\
2 \\
3\end{array}$} & \multirow[t]{2}{*}{$\begin{array}{c}\text { seconds } \\
150 \\
150 \\
195\end{array}$} & \multirow[t]{2}{*}{$\begin{array}{l}66 \\
66 \\
86\end{array}$} & $\begin{array}{l}.015 \\
.015 \\
.012\end{array}$ \\
\hline & & & & & & Average $=.014$ \\
\hline \multirow[t]{2}{*}{$038+585$} & \multirow[t]{2}{*}{4500} & \multirow[t]{2}{*}{.38} & \multirow[t]{2}{*}{$\begin{array}{l}1 \\
2 \\
3\end{array}$} & \multirow[t]{2}{*}{$\begin{array}{l}90 \\
90 \\
85\end{array}$} & \multirow[t]{2}{*}{$\begin{array}{l}42 \\
42 \\
39\end{array}$} & $\begin{array}{l}.025 \\
.025 \\
.036\end{array}$ \\
\hline & & & & & & Average $=.025$ \\
\hline \multirow[t]{2}{*}{ BG1 + GG8 } & \multirow[t]{2}{*}{4650} & \multirow[t]{2}{*}{1.00} & \multirow[t]{2}{*}{$\begin{array}{l}1 \\
2 \\
3\end{array}$} & \multirow[t]{2}{*}{$\begin{array}{l}90 \\
70 \\
70\end{array}$} & \multirow[t]{2}{*}{$\begin{array}{l}90 \\
70 \\
70\end{array}$} & $\begin{array}{l}.011 \\
.014 \\
.014\end{array}$ \\
\hline & & & & & & Average $=.013$ \\
\hline $\mathrm{BG} 1+\mathrm{GG} 7$ & 4850 & .32 & $\begin{array}{l}1 \\
2 \\
3\end{array}$ & $\begin{array}{l}165 \\
195 \\
165\end{array}$ & $\begin{array}{l}53 \\
62 \\
53\end{array}$ & $\begin{array}{c}.019 \\
.016 \\
.019 \\
\text { Average }=.018\end{array}$ \\
\hline \multirow[t]{3}{*}{$352+554$} & \multirow[t]{3}{*}{4900} & \multirow[t]{3}{*}{.19} & \multirow[t]{3}{*}{$\begin{array}{l}1 \\
3\end{array}$} & \multirow[t]{2}{*}{$\begin{array}{l}330 \\
300\end{array}$} & \multirow[t]{2}{*}{$\begin{array}{l}64 \\
58\end{array}$} & $\begin{array}{l}.016 \\
.017\end{array}$ \\
\hline & & & & & & Average $=.016$ \\
\hline & & & & $300(n$ & o response) & \\
\hline 338 & & & & $100(\mathrm{~h}$ & eat response) & \\
\hline
\end{tabular}

The relative number of quanta reaching the skin through each filter should be proportional to the area under the curves. These areas, measured by means of a planimeter, are expressed in relative units as $A$ in Table III.

The threshold time for the erythemal response was determined for each filter, the values for three experiments being given in Table III. Since the reciprocity law holds for light made up of all wavelengths, it may be assumed that it also holds for the restricted spectral bands which pass through the filters. Thus the product of $A$, which is a measure of the relative number of quanta passing a given filter, and the threshold time $t$, should give a value $k_{\lambda}$, which is a measure of the relative number of quanta required to elicit a response at that wavelength. The reciprocal of $k_{\lambda}$ should be a measure of the relative sensitivity at this wavelength, and is the value which may be compared with the absorption of a substance suspected of being the photochemically active agent. Assuming the values of $1 / k_{\lambda}$ to represent the sensitivity of the urticaria solare response at the wavelengths corresponding to the maximum transmissions of the various filters, it would appear that the sensitivity has two wavelength maxima, one at about $4500 \AA$, and another at about $4900 \AA$, 
with a distinct minimum at about $4650 \AA$. That there is little sensitivity above $5000 \AA$ or below $4000 \AA$ was shown clearly by the earlier experiments of Blum, Allington and West (1). Obviously, these values of $1 / k_{\lambda}$ are subject to a considerable degree of error in both parameters, in the one case due to the experimental error involved in determining the threshold, and in the other due to the fact that the band of light transmitted by the filter is rather wide; the degree of error in the latter case cannot be accurately estimated. Another error is introduced, of course, in the determination of the color temperature of the lamp which might somewhat alter the relative values, although this could hardly affect the position of the maxima. At best, these values cannot be considered as very accurate, but they might be expected to give an approximate picture of the absorption spectrum of the photosensitizing substance which is responsible for the urticarial response.

We may now begin our search for the absorption spectrum of some biological substance which will fit this region of absorption with a reasonable degree of approximation. By reference to the data on absorption bands accumulated in Tabulae Biologicae $(16,17,18,19,20)$ we find that only one group of pigments there listed has the maxima of absorption of its members confined to the general spectral region which elicits the urticaria solare response; these are the carotenoids. As pointed out by Blum, Allington and West (1), the porphyrins, which are active photosensitizers, exhibit a minimum of absorption between 4000 and $5000 \AA$ (21) ; the bile pigments show no maxima which will correspond with the region of sensitivity as is also true for cytochrome and hemochromogens in general (22). The flavines, another group of naturally occurring photolabile pigments, absorb in the same general spectral region as the carotenoids ( 4000 to $5000 \AA$ ), but show greater absorption in the near ultraviolet (23); so that if one of these were the sensitizer in the present instance, we should expect to find photosensitivity in the corresponding spectral region where the individual with urticaria solare exhibits little or no sensitivity.

Thus the carotenoids which are definitely photolabile seem to offer the best agreement with our experimental data, and in Figure 11 we have plotted the absorption spectrum of $\alpha$ carotene in alco-

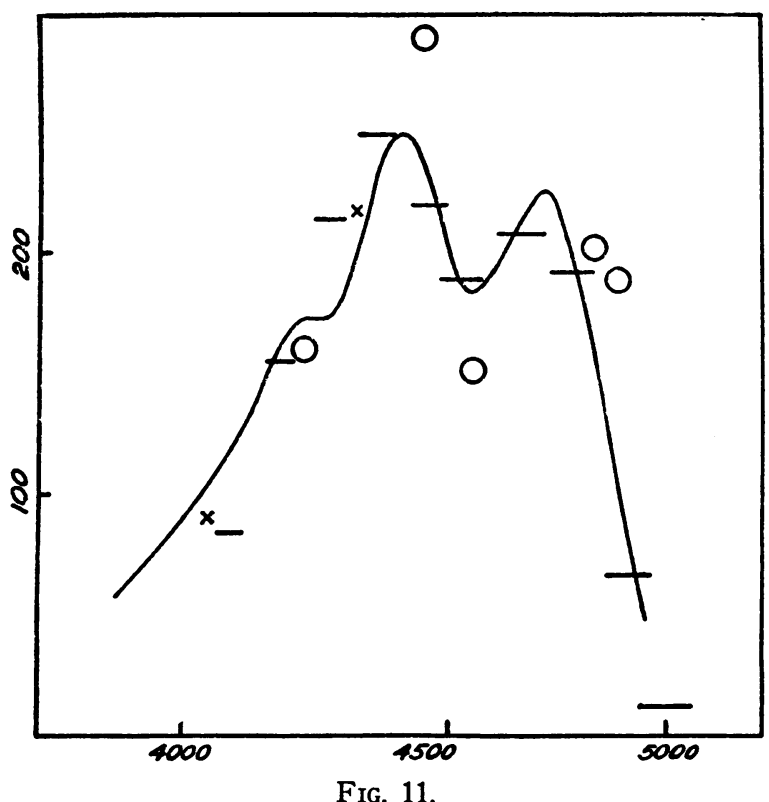

Abscissa-Ångstrom units; ordinates-arbitrary values. Circles-relative sensitivity of urticaria solare $(1 / k)$. Horizontal lines and crosses-relative sensitivity of phototropic bending of the oat seedling. From Johnston (25), corrected to relative number of quanta. Curveabsorption of a carotene in alcohol. From Miller, Mackinney and Zscheile (24).

hol (24), together with our experimentally obtained values $1 / k_{\lambda}$ for the urticaria solare response. In the figure the ordinates for both were chosen so as to bring the absorption curve of $\alpha$ carotene and the values of $1 / k_{\lambda}$ into relationship. It will be seen that at least a rough agreement exists.

In Figure 11 we have also plotted spectral sensitivity data for the phototropic response of the oat seedling, as given by Johnston (25), choosing our ordinates so as to bring the data into accordance with the absorption curve of $\alpha$ carotene. The agreement is rather good, but we could not from this make a categorical statement that $\alpha$ carotene or any other specific carotenoid is the photoactive substance responsible for phototropism in the oat seedling, although we must admit that possibility which has been previously suggested by Bachmann and Bergann (26). We note the existence of two distinct maxima in the data of Johnston corresponding approximately to the 
two maxima in our own data for the urticaria solare response. Other data for the phototropic bending of the oat seedling do not agree quantitatively with that of Johnston (see Bachmann and Bergann (26) ; Haig (27), but all the measurements agree in the delimitation of the general spectral region and in general in the display of two maxima. In considering the data from several sets of measurements on the phototropic bending of the same organism, the oat seedling (Avena sativa), we see that the deviations among the various sets of measurements are as great as the deviation of our own measurements from any one of the above, even though our own data are admittedly of a relatively low degree of accuracy. Thus, so far as the evidence goes the photochemically active substance may be the same in both. Carotenoid pigments have been suspected as the photosensitive materials in phototropic bending of plants, and Castle (28) has been able to extract such a pigment from phycomyces whose absorption spectrum fits well with the spectral sensitivity curve which he has determined for that organism, and which would also approximate our own data and that for the oat seedling. This discussion of the spectral sensitivity of the orienting mechanism in plants has been introduced principally to show the deviation in measurements obtained on other living systems. Numerous factors exist which would create differences between the curves of spectral sensitivity of the living organism, and the absorption curve of the responsible photochemically active substance when removed from the living tissue and in solution in some solvent other than that in which it is dissolved in the organism. For example, the difference in transmissivity of the epidermis to the various active wavelengths might alter the effectiveness of the various spectral bands in eliciting the urticaria solare response; but from the data of Bachem and Reed (9), we may estimate a rather uniform decrease in transmittency of about 15 per cent from 5000 to $4000 \AA$, which could not greatly alter our sensitivity curve. Again, it is unfair to make a comparison of the absorption spectrum of a carotenoid pigment in solution in alcohol with the spectral sensitivity curve of an organism in which the absorbing pigment must be in solution in some other solvent. The ab- sorption spectra of the carotenoids are shifted very markedly with the solvent employed, so that it is impossible to select any specific carotenoid as showing better agreement with the data than another. The choice of $\alpha$ carotene in alcohol for plotting in Figure 11 was made only because it showed the possibility of agreement, not to indicate that this is the actual carotenoid involved. An examination of the absorption spectra in the monograph of Zechmeister (29) will show the extent of the shift of the absorption spectra of carotenoids with the solvent, and will also show that these spectra display two principal maxima separated by a well defined minimum, no matter what the solvent. The apparent existence of two maxima in our measurements of the spectral sensitivity of urticaria solare, and of the phototropism of Avena gives strong support to the hypothesis that carotenoid pigments are responsible for both photo-physiological responses.

Until other evidence is offered, then, we must suspect that a carotenoid pigment is the photosensitizing agent in the case of urticaria solare now in hand, and may use this as a working hypothesis. Following this evidence we have attempted to produce local sensitivity to light by injecting solutions of carotene and xanthophyll into rabbits' ears and into human skin, but exposures of the injected areas to sunlight for periods as long as twenty minutes produced no response which could be taken as definite evidence of photosensitivity. The solvents used for injection were cottonseed oil and propylene glycol. In both cases, particularly the former, a considerable irritation was produced by the injected material which may have masked any response resulting from exposure to light.

\section{DISCUSSION}

The evidence presented in the preceding pages would best be explained by the postulation that a carotenoid pigment is present in the skin, which may be activated by light to set off a series of reactions which result in the release of $H$ substance in the region of the small blood vessels. The ultimate result is the appearance of the triple response on the area of skin reached by the light. The only abnormal part in such a mechanism is the presence of the carotenoid pigment, and it will be well, therefore, to inquire into the plausi- 
bility of the presence of such a pigment, and its possible origin. Carotenoids are taken up in large quantities in the normal diet, a certain fraction being changed into vitamin $\mathrm{A}$, and a large part excreted in the feces. In some cases, after ingestion of great quantities of food rich in carotenoids, enough may accumulate in the skin to give the individual a yellow or reddish color (29). Hess and Myers (30) found that infants fed an excess of carrots assumed a yellow coloration, and that carotene could be isolated from the blood and urine in such cases; there seems to be no record of sensitivity to light, but Klose (31) states that the yellow color is most pronounced on the parts normally exposed to light.

It would seem thus that great quantities of carotenoid pigments may be present in the skin without sensitivity to light, at least in a degree comparable with that of our subject. Moreover, our patient does not show a general yellow tint, so that there can be no great excess of carotenoids. It seems probable that any carotenoid entering the skin from the blood stream would be deposited principally in the fat of the subcutaneous layers because the carotenoids are very soluble in fat and insoluble in water, and the observations of Klose (31) would indicate that this is the point of deposition. The penetration of blue and violet light to the subcutaneous layers is not great, and for reasons discussed above it seems probable that the urticaria solare response is set off in the papillary layer of the corium. It would seem necessary to assume from this that in our subject the carotenoid is deposited superficially to the subcutaneous fat, that it is not present in great quantities, and that it owes its effectiveness as a photosensitizer to its position in the skin or that it is a specific kind of carotenoid which is not ordinarily present in the human organism. All this suggests that the carotenoid may be produced in the skin through the agency of a parasite. It is therefore worthy of remark that our subject displays a few of the yellow macules of Tenia versicolor which result from infection of the skin by the fungus Malasezia furfur, and that it may be this organism which is producing the photosensitizing carotenoid. We have been unable, however, to show that the yellow macular areas are any more sensitive than parts of the skin which appear free from the infection, so that this hypothesis receives no substantiation for the present.

\section{SUMMARY}

Photo-physiological studies of an urticarial response elicited by blue and violet light demonstrate the following.

1. The response obeys the reciprocity law.

2. Studies of the effect of temperature indicate that the mechanism of the response includes a photochemical reaction which is not greatly affected by temperature, and a thermal reaction which is greatly modified by changes in temperature. The latter is probably the action of a histamine-like substance on the small vessels of the skin.

3. All parts of the body are sensitive to light but the degree of sensitivity varies from region to region. The exposed parts are much less sensitive than the parts covered by clothing. The reasons for these variations are discussed.

4. The sensitivity fluctuated somewhat with time, but there was no general trend in the course of ten months.

5. Determination of the spectral sensitivity suggests that the photosensitizer is a carotenoid pigment. The possible origin of such a carotenoid in the skin is discussed.

We wish to express our appreciation of the assistance graciously given by the following: Dr. H. V. Allington who made the clinical studies; Professor L. M. K. Boelter who determined color temperatures of lamps; Professor Eric Ogden for histamine tests; Professor A. P. Krueger for bacteriological control of materials for injection; and Doctors G. Mackinney and S. Lepkovsky who provided samples of xanthophyll and carotene.

\section{BIBLIOGRAPHY}

1. Blum, H. F., Allington, H., and West, R., On an urticarial response to light and its photophysiology. J. Clin. Invest., 1935, 14, 435.

2. Lewis, T., The Blood Vessels of the Human Skin and Their Responses. Shaw and Sons, London, 1927.

3. Harrison, G. R., Instruments and methods used for measuring spectral light intensities by photography. J. Optic. Soc. America, 1929, 19, 267.

4. Luckiesch, M., Artificial Sunlight Combining Radiation for Health with Light for Vision. Van Nostrand, New York, 1930, p. 165.

5. Holladay, L. L., Proportion of energy radiated by incandescent solids in various spectral regions. $\mathrm{J}$. Opt. Soc. America, 1928, 17, 329. 
6. Duke, W. W., Urticaria caused by light. Preliminary report. J. A. M. A., 1923, 80, 1835.

7. Vallery-Radot, P., Blamoutier, P., Besançon, J., and Saidman, J., Urticaire solaire. Bull. et mém. Soc. méd. d. hôp. de Paris, 1926, 50, 1116.

8. Miescher, G., Das Problem des Lichtschutzes und der Lichtgewöhnung. Strahlentherapie, 1930, 35, 403.

9. Bachem, A., and Reed, C. I., The penetration of light through human skin. Am. J. Physiol., 1931, 97, 86.

10. Laurens, $H$., Photochemistry in medicine. A general outline. Cold Spring Harbor Symposia on Quantitative Biology, 1935, 3, 277.

11. Duke, W. W., Allergy, Asthma, Hay Fever, Urticaria, and Allied Manifestations of Disease. C. V. Mosby Co., St. Louis, 1925.

12. Blum, H. F., Watrous, W. G., and West, R. J., On the mechanism of photosensitization in man. Am. J. Physiol., 1935, 113, 350.

13. Thompson, F., About bee venom. Lancet, 1933, 225, 446.

14. Frei, W., Lokale urtikarielle Hautreaktion auf Sonnenlicht. Arch. f. Dermat. u. Syph., 1925, 149, 124.

15. Blum, H. F., and Scott, K. G., Photodynamically induced tropisms in plant roots. Plant Physiol., 1933, 8, 525.

16. Brigl, P., Pflanzliche Farbstoffe. Tabulae Biologicae, 1926, 3, 333 and 338.

Fischer, H., and Treibs, Tierische Farbstoffe. Ibid., pp. 349 to 361 .

17. Kirstahler, A., Blut-Farbstoff und Derivate Spektren des Farbstoff-Anteils des Hämoglobins u. seiner Umwandlungsprodukte. Tabulae Biologicae, 1931, 7, pp. 66 to 87.

Chlorophyll a und b, ihre Umwandlungs-bezw. Abbau Produkte II. Ibid., pp. 245 to 257.

18. Karrer, P., Carotinoide. Tabulae Biologicae, 1933, 8, 342.
19. Fernholz, E., Vitamin $B_{1}, B_{2}, C$ und D. Tabulae Biologicae, 1934, 9, pp. 196 to 202.

20. Haurowitz, F., Respiratorische Farbstoffe (Chromoproteide). Tabulae Biologicae, 1935, 10, pp. 25 to 28.

21. Clar, E., and Haurowitz, F., Die Konstitution der Porphyrine. Ber. deutsch. chem. Gesell., 1933, 66, 331.

22. Roche, J., and Bénévent, M., Recherches sur la constitution du cytochrome c. Bull. Soc. chim. biol., 1935, 17, 1473.

23. Kuhn, R., György, P., and Wagner-Jauregg, T., Utber Ovoflavin, den Farbstoff des Eiklars. Berl. d. deutsch. chem. Gesell., 1933, 66, 576.

24. Miller, E. S., Mackinney, G., and Zscheile, F. P., Absorption spectra of alpha and beta carotenes and lycopene. Plant Physiol., 1935, 10, 375.

25. Johnston, E. S., Growth Movements in Relation to Radiation. (Chapter XXXIII in Biological Effects of Radiation. Edited by B. M. Duggar.) McGraw-Hill Co., New York, 1936.

26. Bachmann, Fr., and Bergann, Fr., Über die Wertigkeit von Strahlen verschiedener Wellenlänge für die phototropische Reizung von Avena sativa. Planta: Archiv. Wiss. Bot., 1930, 10, 744.

27. Haig, C., The spectral sensibility of Avena. Proc. Nat. Acad. Sc., 1934, 20, 476.

28. Castle, E. S., Photic excitation and phototropism in single plant cells. Cold Spring Harbor Symposia on Quantitative Biology, 1935, 3, 224.

29. Zechmeister, L., Carotinoide. Springer, Berlin, 1934.

30. Hess, A. F., and Myers, V. C., Carotinemia: A new clinical picture. J. A. M. A., 1919, 73, 1743.

31. Klose, E., Hautverfärbung bei Säuglingen und Kleinkindern infolge der Nahrung. München med. Wchnschr., 1919, 66, 419. 